\title{
ALIENAÇÃO PARENTAL ESTATAL
}

\author{
Daniele Bellettato Nesrala ${ }^{1}$ \\ Tereza Cristina Sorice Baracho Thibau ${ }^{2}$
}

RESUMO: O estudo analisa relatórios e decisões judiciais, à luz do sistema normativo vigente, demonstrando que a alienação parental pode ser praticada pelo Estado-guardião de crianças e adolescentes submetidos à medida de proteção de acolhimento institucional. Estes infantes são levados a acreditar que seus pais os abandonaram. Em verdade, não foram reintegrados em suas famílias de origem por conclusões preconceituosas, eivadas de violência institucional, discriminação estrutural e inobservância pelo Estado ao direito de defesa e devido processo legal. Estes infantes encontram grande dificuldade para superar os traumas da alienação parental que sofreram enquanto estiveram sob a guarda do Estado.

Palavras-Chave: Direito da Criança e do Adolescente. Alienação Parental Estatal. Acolhimento Institucional. Discriminação Estrutural. Violência Institucional.

\section{STATE PARENTAL ALIENATION}

\begin{abstract}
The study analyzes reports and judicial decisions in the current normative system, demonstrating that parental alienation can be practiced by the guardian-State of children and adolescents in institutional shelter protection. These infants are forced to believe that their parents had abandoned them. Actually, they were not reintegrated in their families by prejudicial conclusions, outbreaks of institutional violence, structural discrimination and lack of compliance by the State with the right to defense and due process of law. These children have difficulty to overcome their traumas caused by parental alienation that suffered while they were under protection in guard of State.
\end{abstract}

Keywords: Right of children and adolescents. State parental alienation. Institutional shelter. Structural discrimination. Institutional violence.

\footnotetext{
${ }^{1}$ Mestranda em Direito pela Universidade Federal de Minas Gerais; Defensora Pública do Estado de Minas Gerais; membro fundador do IBDCRIA (Instituto Brasileiro de Direitos da Criança e do Adolescente); membro da Comissão da Infância e Juventude da ANADEP (Associação Nacional de Defensores Públicos); Endereço postal Av Professor Mário Werneck, 3180, 803, Buritis, Belo Horizonte, MG, CEP 30575-180; Endereço eletrônico: danibellettato@gmail.com;

${ }^{2}$ Doutora em Direito pela Universidade Federal de Minas Gerais. Foi Subcoordenadora do Programa de Pós-Graduação da Faculdade de Direito da Universidade Federal de Minas Gerais (2008 - 2011). Foi Professora Assistente (1996-2003) e Professora Adjunta na Faculdade de Direito da UFMG (2003-2011). É Professora Associada na Faculdade de Direito da UFMG desde 05/2011 lecionando nos cursos de graduação (direito processual civil) e pós-graduação (direito e processo coletivo). Vice Diretora da Divisão de Assistência Judiciária da Faculdade de Direito da Universidade Federal de Minas Gerais (1996-1998 e 2010-2016). Membro do Instituto de Direito Processual (IDPro). Endereço postal: Av. João Pinheiro, 100, Centro, Belo Horizonte, MG, CEP 30130-180; Endereço eletrônico: tthibau@gmail.com;
} 


\section{INTRODUÇÃO}

A alienação parental consiste na prática de atos por quem quer que detenha a guarda legal ou judicial de criança ou adolescente com o propósito de fazer com que repudie um dos genitores. E, não obstante a maioria dos estudos científicos sobre tema fazerem referência exclusiva àquela praticada por um dos genitores ou parente guardião, o presente estudo pretende demonstrar que não apenas familiares, mas o Estado também pode praticar alienação parental, especialmente durante a aplicação e execução de medidas de acolhimento institucional de crianças e adolescentes, quando os têm sob sua guarda.

A pesquisa foi realizada em caráter interdisciplinar, envolvendo as áreas do direito, da sociologia, da psicologia, da medicina e da assistência social, bem como por meio de processos de estudo histórico e exploratório, com a análise de casos concretos e dados estatísticos fornecidos pelo Tribunal de Justiça de Minas Gerais e pela Secretaria de Assistência Social de Belo Horizonte. Importante ressalvar que, em razão do segredo de justiça que se impõe aos processos atinentes à Vara da Infância e Juventude, os números de processos, nomes das partes e dos técnicos, autores das afirmações contidas em relatórios sociais e transcritas neste trabalho, não serão identificados.

Inicialmente serão demonstradas as mudanças axiológicas impostas ao direito de família ao longo do tempo, que levaram aos conceitos modernos de poder familiar e alienação parental. A seguir, será analisada a alienação parental, em seus aspectos psicológicos e jurídicos.

O tema central deste estudo é a alienação parental praticada pelo Estado, especialmente aquela que se verifica no bojo da aplicação e execução de Medidas de Proteção de Acolhimento Institucional de bebês, crianças e adolescentes. São analisados três exemplos emblemáticos da alienação parental estatal que ocorrem durante o acolhimento institucional: violência obstétrica, discriminação estrutural e cerceamento de defesa imposto às famílias naturais ou extensas de infantes abrigados.

As consequências pela prática da alienação parental estatal são danosas e irreversíveis, o que torna imperiosa a capacitação continuada de todos os profissionais envolvidos neste processo, de modo que reconheçam e não acolham tendências preconceituosas e 
discriminatórias, que ensejam indevida intervenção estatal no âmbito familiar e de modo tão gravoso,

\section{A EVOLUÇÃO DO DIREITO DE FAMÍLIA}

A Família é a base da sociedade e do Estado, como reconhecido expressamente pelo artigo 226 da Constituição da República de 1988 (CR 88), sendo atemporal e universalmente reconhecida, ainda que em cada sociedade a família possa assumir uma conformação diferenciada.

O termo família, apesar de vago, pode significar: a) o grupo composto de pais e filhos; b) uma linhagem patrilinear; c) um grupo de pessoas que descendem de um mesmo antepassado, homens ou mulheres; d) um grupo de parentes que vivem juntos. (MELLO, 2009, p 326)

Durante séculos, a família apresentou-se como instituição patriarcal, fundada no matrimônio, com nítida ênfase para a defesa dos direitos patrimoniais. E, até pouco tempo atrás, o ordenamento jurídico brasileiro só tratava dos institutos do casamento, filiação e parentesco.

As relações de afeto e extrapatrimoniais só começaram a interessar ao Direito de Família Brasileiro com as transformações sociais impostas pelas novas conformações práticas e conceituais de família, passando a ter especial relevância a solidariedade, afeto, confiança e respeito, bem como a substituição da prevalência de famílias patriarcais por matriarcais.

No âmbito do direito de família, a Constituição da República de 1988 (CR/88) elegeu a dignidade da pessoa humana como paradigma essencial e objetivo fundamental do Estado Democrático de Direito ${ }^{3}$, incluindo novos princípios constitucionais ${ }^{4}$, que acabaram por impor uma ampla revisão nos valores familiares e nos conceitos de família e do próprio direito de família:

"núcleo existencial integrado por pessoas unidas por vínculo socioafetivo, teleologicamente vocacionada a permitir a realização

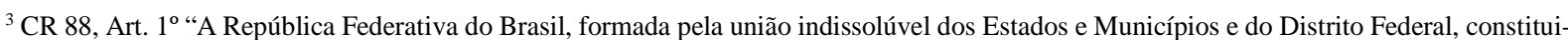
se em Estado Democrático de Direito e tem como fundamentos: (...) III - a dignidade da pessoa humana;”

${ }^{4}$ Princípios Constitucionais do Direito de Família apontados pela doutrina: Princípio da afetividade; Principio da solidariedade familiar; Principio da igualdade entre pais e filhos, entre cônjuges ou companheiros e na chefia familiar; Princípio proteção ao idoso; Princípio da função social da família; Principio da plena proteção das crianças e adolescentes; Princípio da convivência familiar; Principio da intervenção mínima do Estado no Direito de Família; Princípio da boa-fé objetiva (GAGLIANO, Pablo Stolze. Manual de direito civil; volume único. São Paulo, Saraiva, 2017; TARTUCE, Flávio. Direito Civil, v. 5: Direito de Família. 12 ed. Rio de Janeiro. Forense, 2017)
} 
plena dos seus integrantes, segundo o principio constitucional da pessoa humana”. (GAGLIANO, 2017, p. 1081)

"Família no sentido amplíssimo seria aquela em que indivíduos estão ligados pelo vínculo da consanguinidade ou da afinidade. Já a acepção lato sensu do vocábulo refere-se aquela formada além dos cônjuges ou companheiros, e de seus filhos, abrange os parentes da linha reta ou colateral, bem como os afins (os parentes do outro cônjuge ou companheiro). Por fim, o sentido restrito restringe a família à comunidade formada pelos pais (matrimônio ou união estável) e a da filiação. (DINIZ, 2008, p.09)

Os novos arranjos familiares evoluíram acompanhando a dinâmica social, e fazendo com que o direito de família também evolua, inicialmente por meio da jurisprudência e, ao final, pelas alterações no plano normativos.

Recentemente, o Supremo Tribunal Federal (STF), quando do julgamento do Recurso Extraordinário 898.060, admitiu expressamente a possibilidade da parentalidade socioafetiva e a multiparentalidade, afirmando, o relator, Ministro Luiz Fux, que "a paternidade socioafetiva, declarada ou não em registro, não impede o reconhecimento do vínculo de filiação concomitante, baseada na origem biológica, com efeitos jurídicos próprios”.

O provimento $n^{\circ}$ 63, de 14 de novembro de 2017, do Conselho Nacional de Justiça (CNJ), em seu artigo 10, autorizou o reconhecimento voluntário da paternidade ou da maternidade socioafetiva diretamente perante os oficiais de registro civil das pessoas naturais, sem a necessidade de que haja um reconhecimento judicial para que a multiparentalidade possa surtir os devidos efeitos jurídicos.

Assim, a ordem constitucional vigente consagrou uma estrutura familiar paradigmática aberta, calcada no princípio da afetividade, visando a permitir, ainda que de forma implícita, a evolução dos institutos do direito de família, com o reconhecimento de outros ninhos ou arranjos familiares socialmente constituídos (GAGLIANO, 2017).

Dentre os institutos do direito de família que sofreram grandes modificações pelas novas configurações de família está o exercício das funções parentais.

Com a evolução do conceito de família e seus institutos, bem como a constitucionalização do direito de família gerou alterações nos direitos e deveres na sociedade conjugal $^{5}$, equiparando homens e mulheres. A expressão “pátrio poder” cedeu lugar à expressão

${ }^{5} \mathrm{CF}$ 88, Art. 226, § 5º Os direitos e deveres referentes à sociedade conjugal são exercidos igualmente pelo homem e pela mulher. 


\section{ALIENAÇÃO PARENTAL ESTATAL}

"poder familiar", adotada expressamente pelo Código Civil de $2002^{6}$, entretanto, embora parte da doutrina prefira utilizar a expressão “autoridade parental”, como leciona Flávio Tartuce:

“Nessa linha, nas justificativas da proposição é expresso que o termo autoridade se coaduna com o princípio de melhor interesse dos filhos, além de contemplar a solidariedade familiar. O Art. 87 do projeto determina que "A autoridade parental deve ser exercida no melhor interesse dos filhos”. (TARTUCE, 2017, p. 271)

A Autoridade parental pode ser melhor definida como:

"direito subjetivo dos pais exercido no interesse destes e dos filhos; como um poder jurídico exercício em beneficio do outro sujeito da relação. Fato é que a autoridade parental vista como relação de poder-sujeição está em crise. O que têm em comum todas essas definições do instituto denominado pelo legislador infracionstitucional de poder familiar é que esse deve ser exercício no interesse dos filhos.

Assim, na concepção contemporânea, a autoridade parental não pode ser reduzida nem a uma pretensão juridicamente exigível em favor dos seus titulares nem a um instrumento jurídico de sujeição (dos filhos à vontade dos pais)”. (MULTEDO, 2017, p. 108).

O poder familiar ou autoridade parental, portanto, consiste num conjunto de direitos e deveres que o guardião tem em relação a crianças e adolescentes e que estão exemplificativamente elencados no artigo 1634 do CC 02 e o uso abusivo desta autoridade pode acarretar alienação parental.

\section{DA ALIENAÇÃO PARENTAL}

A alienação parental consiste no uso indevido da guarda legal ou judicial para manipular a criança ou adolescente sob responsabilidade do alienante, com a finalidade de denegrir a imagem de um dos genitores e afastar o infante do convívio destes, fazendo com que o infante repudie um dos genitores ou que cause prejuízo ao estabelecimento ou à manutenção de vínculos com este, como leciona

Muitas vezes, quando da ruptura da vida conjugal, se um dos cônjuges não consegue elaborar adequadamente o luto da separação, o sentimento

${ }^{6}$ CC 02, Art. 1.630. Os filhos estão sujeitos ao poder familiar, enquanto menores. 
de rejeição, ou a raiva pela traição, surge um desejo de vingança que desencadeia um processo de destruição, de desmoralização, de descrédito do ex-parceiro. (...) Trata-se de verdadeira campanha de desmoralização. A criança é levada a afastar-se de quem ama e de quem também a ama. Nesse jogo de manipulações, todas as armas são utilizadas, inclusive a assertiva de ter havido abuso sexual. O filho é convencido da existência de determinados fatos e levado a repetir o que lhe é afirmado como tendo realmente acontecido. Nem sempre consegue discernir que está sendo manipulado e acaba acreditando naquilo que lhe foi dito de forma insistente e repetida. Com o tempo, nem o alienador distingue mais a diferença entre verdade e mentira. A sua verdade passa a ser verdade para o filho, que vive com falsas personagens de uma falsa existência, implantando-se, assim, as falsas memórias. (DIAS, 2011. p. 463)

Tal prática afeta diretamente o direito fundamental de crianças e adolescentes viola o princípio da dignidade da pessoa humana, além de ferir o direito fundamental da criança ou do adolescente de convivência familiar saudável sadia convivência familiar, conforme preconizado pelo artigo 227 da CR/88 e artigo 19 do ECA. Também prejudica a relação de afeto entre infante e genitores e constitui abuso moral e descumprimento dos deveres inerentes à autoridade parental ou decorrentes de tutela ou guarda.

\subsection{AsPECTOS PSICOLÓGICOS DA ALIENAÇÃO PARENTAL}

A prática reiterada de atos de alienação parental pode acarretar graves consequências emocionais e comportamentais, denominadas pela psicologia de síndrome da alienação parental.

A criança alienada passa a apresentar um sentimento constante de raiva e ódio contra o genitor alienado e sua família, recusando-se a visitar ou comunicar-se com o outro genitor, além de guardar sentimentos e crenças negativas inverídicas sobre o outro genitor. Tal forma de abuso moral irá refletir na formação da sua personalidade, especialmente no desenvolvimento dos laços afetivos familiares, necessários à boa estruturação psicossocial deste indivíduo.

A síndrome de alienação parental é um transtorno psicológico que se caracteriza por um conjunto de sintomas pelos quais um genitor, denominado cônjuge alienador, transforma a consciência de seus filhos, mediante diferentes formas e estratégias de atuação, com o objetivo de 
impedir, obstaculizar ou destruir seus vínculos com o outro genitor, denominado cônjuge alienado, sem que existam motivos reais que justifiquem essa condição. (TRINDADE, 2007, p. 113)

A alienação parental não se confunde com Síndrome da Alienação parental. A primeira diz respeito aos atos praticados pelo guardião visando impor o afastamento da criança de um de seus genitores. Já a segunda refere-se às consequências psicológicas causadas na criança, em razão da prática de atos de alienação parental.

\subsection{ASPECTOS JURÍDICOS DA ALIENAÇÃO PARENTAL}

A lei federal 12.318 de 26 de Agosto de 2010 (Lei da Alienação parental - LAP 2010) passou a definir o instituto da alienação parental e a impor consequências jurídicas ao alienante que venha a praticá-la.

Importante atentar que o artigo $2^{\circ}$ da LAP prevê a possibilidade do ato de alienação parental ser praticado por quem quer que detenha a guarda:

Art. $2^{\circ}$ Considera-se ato de alienação parental a interferência na formação psicológica da criança ou do adolescente promovida ou induzida por um dos genitores, pelos avós ou pelos que tenham a criança ou adolescente sob a sua autoridade, guarda ou vigilância para que repudie genitor ou que cause prejuízo ao estabelecimento ou à manutenção de vínculos com este. (Grifos nossos)

A alienação parental pode se manifestar por meio de várias condutas, desde a dificuldade de contato telefônico com a criança, da desqualificação moral do pai ou da mãe, denegrindo-lhe a imagem, até situações mais graves como acusações falsas de violência física, abuso psicológico ou sexual. De qualquer forma, o objetivo final da prática de tais atos será sempre o de destruir o vínculo afetivo entre o filho e o genitor alienado. O artigo $2^{\circ}$, parágrafo único, da LAP elenca alguns exemplos.

Diante de quaisquer condutas que caracterizem ato de alienação parental, as medidas que poderão ser impostas pelo juiz ao genitor alienante, estão estabelecidas no artigo $7^{\circ}$ da LAP.

As consequências advindas do ato de alienação parental podem variar desde a simples declaração judicial da ocorrência da alienação e advertência ao alienador para que modifique sua conduta e até mesmo impor a formal perda da guarda pelo alienante, podendo o juiz suspender-lhe o poder familiar, a depender da gravidade do ato.

Revista Brasileira de Direito Civil em Perspectiva | e-ISSN: 2526-0243 | Salvador | v. 4 | n. 1 | p. 39 - 60 | Jan/Jun. 2018 
A intervenção estatal, por meio da aplicação das medidas previstas no artigo $7^{\circ}$ da LAP justifica-se na medida em que atos de impedir ou dificultar o contato dos filhos com o genitor alienado é um ato que trará consequências danosas e irreversíveis aos filhos, que estão em processo de formação da personalidade.

Nesse sentido, leciona Rodrigo da Cunha Pereira:

“O Estado abandonou a sua figura de protetor-repressor, para assumir postura de Estado protetor-provedor-assistencialista, cuja tônica não é de uma total ingerência, mas em algumas vezes, até mesmo de substituição à eventual lacuna deixada pela própria família, como, por exemplo, no que concerne à educação e saúde dos filhos (cf. art. 227 da Constituição Federal). A intervenção do Estado deve apenas e tão somente ter o condão de tutelar a família e dar-lhe garantias, inclusive de ampla manifestação de vontade e de que seus membros vivam em condições propicias à manutenção do núcleo afetivo.” (PEREIRA, 2012, p. 157)

A legislação autoriza a intervenção estatal sempre que crianças e adolescentes estiverem em situação de risco, conforme previsto no artigo 98 do ECA/90, seja em decorrência de ação ou omissão da sociedade ou Estado; falta, omissão ou abuso dos pais ou responsáveis e em razão de conduta do próprio infante.

Nos casos de verificação de crianças e adolescente em situação de risco, são aplicáveis as medidas de proteção descritas no art. 101 do ECA/90, dentre elas o acolhimento institucional ou familiar.

Durante a execução da medida de acolhimento institucional a criança ou adolescente fica sob a guarda ou tutela do dirigente da entidade de acolhimento institucional, por força do disposto no art. 92, §1 ${ }^{\circ}$, do ECA 90.

E nesta situação, o Estado, como titular do serviço público ${ }^{7}$ de acolhimento institucional, é o responsável pelos atos praticados contra crianças e adolescentes no âmbito de entidades de acolhimento, seja por meio de execução direta ou indireta do serviço, incorrendo o Estado na prática de alienação parental quando promove a indevida e definitiva separação de pais e filhos.

\section{DA ALIENAÇÃO PARENTAL ESTATAL}

A alienação parental estatal é frequentemente revelada pela prática reiterada de discriminação estrutural e/ou violência institucional durante a aplicação de medidas de acolhimento institucional, previstas nos artigos 98 e 101 do ECA/90.

\footnotetext{
${ }^{7}$ Serviço Público pode ser conceituado como "Toda atividade prestada pelo Estado ou por seus delegados, basicamente sob regime de direito público, com vistas à satisfação de necessidades essenciais e secundárias da coletividade” (CARVALHO FILHO, 2007, p. 281).
}

Revista Brasileira de Direito Civil em Perspectiva | e-ISSN: 2526-0243 | Salvador | v. 4 | n. 1 | p. 39 - 60 | Jan/Jun. 2018 
Nestas situações, crianças e adolescentes são levados a crer que suas famílias os abandonaram sendo que, em verdade, não foram reintegrados em suas famílias de origem por razões preconceituosas, discriminatórias e higienistas. Os genitores estão impedidos de visitar os filhos institucionalizados e ainda têm cerceado seu efetivo direito à defesa no procedimento que lhes impôs o afastamento.

Quando estes indivíduos completam 18 anos e são desinstitucionalizados, são entregues à própria sorte e, sozinhos no mundo, acabam buscando apoio em suas famílias biológicas e encontram grande dificuldade para superar os traumas da alienação parental que sofreram enquanto estiveram sob a guarda do Estado.

\subsection{Alienação parental estatal decorrente de Medidas de Acolhimento Institucional}

Diante da imposição legislativa, o acolhimento institucional é medida drástica, que rompe bruscamente o contato entre pais e filhos, acarretando danos certos e irreversíveis ao desenvolvimento do individuo. Por isso deve ser utilizado de modo excepcionalíssimo; deve durar o menor tempo possível; ser determinado em procedimento contencioso, em que se assegure a ampla defesa e o contraditório e seja prioritariamente diligenciada a reintegração familiar.

A reintegração familiar pode ser feita para a família natural ou extensa. Por família natural entende-se a comunidade formada pelos pais ou qualquer deles e seus descendentes e por família extensa endente-se aquela formada por parentes próximos com os quais a criança ou adolescente convive e mantém vínculos de afinidade e afeto, na forma do artigo 25 do ECA/90.

A alienação parental estatal caracteriza-se pelo o afastamento de uma criança do seio de sua família por suposta precaução, mediante medida cautelar, sem que especificamente nenhuma situação de risco atual e iminente tenha efetivamente acontecido, baseando-se apenas em presunções e pré-conceitos. 
Conforme será demonstrado, não são raros os trabalhos científicos que analisam as ações estatais tendentes a intervir indevidamente no âmbito familiar, promovendo indevida separação de pais e filhos por meio da utilização da medida de acolhimento institucional como primeira opção para o enfrentamento da situação de risco a que a criança possa estar exposta. O ECA/90 estabelece que tal medida deve ser a última a ser adotada e só ser aplicada após esgotadas todas as outras opções.

Por exemplo, o caso de uma criança submetida à violência física não deve receber, como primeira medida de proteção, o acolhimento. Em primeiro lugar, deve o agressor ser encaminhamento para tratamento e acompanhamento pela rede de proteção, especialmente pelo Conselho Tutelar. Em caso de ineficácia destas medidas o agressor é que deve ser afastado do lar ou ainda, a criança pode ser colocada sob a guarda de algum familiar, na forma prevista nos artigos 100 e 101 do ECA/90. Impor o acolhimento institucional, como primeira opção, à criança vítima de abusos ou maus tratos é penaliza-la ainda mais gravemente com segregação social e familiar.

Por outro lado, também não é raro deparar-se com situações em que os agentes estatais, imbuídos de uma visão higienista e altamente discriminatória, tendem a dificultar a manutenção e reintegração dos vínculos familiares, focando na preferência da inserção da criança em famílias com boas condições financeiras, livres de comportamentos considerados inadequados em detrimento de suas famílias biológicas, pobres ou miseráveis, como estabelecido pelo artigo 19, parágrafo $3^{\circ}$ do ECA/90.

Estas condutas acabam resultando acolhimentos massivos, instituindo uma política de discriminação estrutural e de alienação parental estatal, além de revelar retrocesso à doutrina menorista, conforme adverte KREUZ, 2012:

Na doutrina anterior, da situação irregular, a criança e o adolescente eram considerados sujeitos de direitos somente quanto encontrados em situações irregulares, ou de patologia social, assim definidos em lei, como nos casos de prática de atos infracionais, abandono, orfandade, etc. A doutrina da situação irregular foi adotada no Brasil pelos Códigos de Menores de 1927 e 1979, mas não foi suficiente ara enfrentar os problemas da infância pobre e abandonada. A criança, neste contexto, só tinha importância para o Poder Público, quando se fizesse notar pela sua situação de "irregularidade" como a delinquência, o abandono, orfandade, etc. Com isso, surgiu a ideia de que o Estado poderia suprir o que a família não quisesse ou não pudesse realizar, no sentido de assistir, 
ALIENAÇÃO PARENTAL ESTATAL

disciplinar, educar as crianças que se encontrassem em situações ditas irregulares. Iniciaram-se, assim, os acolhimentos em massa, em grandes unidades de internação. Assim, o "menor" que era vítima de maus-tratos, de violência doméstica, de abandono era tratado como um sujeito em situação irregular, razão que justificava seu afastamento da família e seu consequente acolhimento institucional. Com a Constituição Federal de 1988, no entanto, inaugura-se a transição de um modelo para outro. Custódio explica que em consequência disso, a legislação foi atualizada, produzindo um reordenamento de planos, projetos, ações e atitudes, tanto por parte do Poder Público como da sociedade, com reflexos altamente positivos. (KREUZ, 2012, p. 64).

Na atualidade, nota-se uma tendência à criminalização da pobreza que acaba gerando inúmeros acolhimentos institucionais desnecessários e, não raro, separam definitivamente a criança de sua família natural, de sua origem sociocultural e de sua história de vida.

Pela análise dos dados fornecidos pelo Serviço de Orientação e Fiscalização às Entidades da Vara Cível da Infância e Juventude de Belo Horizonte (MINAS GERAIS, 2017) e pela Secretaria Adjunta de Assistência Social da Prefeitura de Belo Horizonte (BELO HORIZONTE, 2017), apurou-se que, desde 2013, quintuplicou o número de crianças acolhidas diretamente das maternidades públicas na Comarca de Belo Horizonte. Foram 468 bebês separados de suas mães logo após o nascimento, ainda nas maternidades públicas, e encaminhados diretamente para instituições de acolhimento.

Por outro lado, os dados da saída de bebês de zero a doze meses das casas de acolhimento, no mesmo período, revelam que quase 70\% destes bebês não foram restituídos às suas famílias natural ou extensa, mas foram encaminhados para adoção, invertendo-se, pois, a lógica protetiva instalada pelo ECA/90.

Estes bebês têm sido retirados da companhia de suas respectivas mães e famílias biológicas, após o parto, diretamente das maternidades públicas, ao argumento de que suas famílias estariam em alguma situação de vulnerabilidade ou suspeita de risco, sendo sumariamente retiradas de suas famílias.

A seguir, serão abordadas algumas formas de alienação parental estatal reveladas no âmbito da Medida Protetiva de Acolhimento Institucional:

Revista Brasileira de Direito Civil em Perspectiva | e-ISSN: 2526-0243 | Salvador | v. 4 | n. 1 | p. 39 - 60 | Jan/Jun. 2018 


\subsubsection{Da violência obstétrica}

A violência obstétrica ${ }^{8}$ é caracterizada por qualquer ato praticado pelo médico, pela equipe do hospital, por um familiar ou acompanhante que ofenda, de forma verbal ou física, as mulheres gestantes, em trabalho de parto ou, ainda, no período puerpério.

Contudo, vem se tornando cada vez mais frequente, o acolhimento de recém nascidos, direto das maternidades, revelando hipótese de violência institucional.

Essa abrupta separação de mãe e filho logo após o parto, que caracteriza violência obstétrica, também configura ato de alienação parental praticadas por agentes estatais, passíveis de repúdio, nos termos do artigo $6^{\circ}$ da LAP, que prevê uma série de medidas protetivas do infante, sem prejuízo da responsabilidade civil e criminal do agente.

A Promotoria da Infância e Juventude Cível de Belo Horizonte editou em 2014 as recomendações de números 05 e 06, pelas quais profissionais de saúde de maternidades públicas deveriam encaminhar diretamente à Vara da Infância os recém-nascidos de famílias que apresentem vulnerabilidades como pobreza extrema, alcoolismo ou uso de drogas, negligencias ou maus tratos a nascituros ou recém nascidos, ai incluídas as gestantes que não realizem o prénatal.

A interpretação do que se considera maus tratos e negligência foi extremamente alargada, já tendo sido constatados casos em que foi imposto o afastamento no qual a mãe havia sido vítima de violência doméstica cerca de 2 anos antes do parto; casais que vivem em zona rural e não tiveram acesso a pré-natal; genitores com algum tipo de deficiência mental, ainda que com o auxílio de familiares; genitores que declaram que usaram drogas durante a gestação, independentemente da constatação de dependência química que incapacite os genitores para o exercício da maternagem. Outro fator de destaque é que tais recomendações, geralmente, são dirigidas exclusivamente a maternidades públicas, revelando o nítido caráter discriminatório e higienista:

\footnotetext{
${ }^{8}$ Lei do Estado de Santa Catarina N 17.097 , DE 17 DE JANEIRO DE 2017

Art. $2^{\circ}$ Considera-se violência obstétrica todo ato praticado pelo médico, pela equipe do hospital, por um familiar ou acompanhante que ofenda, de forma verbal ou física, as mulheres gestantes, em trabalho de parto ou, ainda, no período puerpério.

Art. $3^{\circ}$ Para efeitos da presente Lei considerar-se-á ofensa verbal ou física, dente outras, as seguintes condutas:

$\underline{X I X}$ - retirar da mulher, depois do parto, o direito de ter o bebê ao seu lado no Alojamento Conjunto e de amamentar em livre demanda, salvo se um deles, ou ambos necessitarem de cuidados especiais; (Grifos Nossos)
} 
As práticas carregadas de significados culturais estereotipados de desvalorização e submissão da mulher, atravessadas pelas ideologias médica e de gênero, se tornam naturalizadas na cultura institucional. Esses significados favorecem as condições de existência e perpetuação desse tipo de violência que, por sua vez, não deve ser compreendida apenas como reflexo das precárias condições de trabalho dos profissionais. (...) Além das intervenções obstétricas desnecessárias, muitas mulheres relatam vivências de parto dolorosas, com ofensas, humilhação e expressão de preconceitos arraigados em relação à saúde e à sexualidade da mulher. Essa realidade é cotidiana e cruel e revela uma grave violação dos direitos humanos e direitos das mulheres (ZANARDO, 2017).

Nessa situação, após nove meses de gestação, enquanto o bebê encontrava-se vinculado física e emocionalmente à genitora, dela é bruscamente separado, e em seguida encaminhado para uma instituição de acolhimento, que, via de regra, restringe a visitação da mãe e a amamentação a apenas uma hora por semana. Olvida-se que o aleitamento materno, além de alimento ao recém-nascido, também tem a importante função de desenvolver os laços de amor e proximidade deste com sua genitora.

John Bowlby (1907-1990), psiquiatra e psicanalista britânico, que desenvolveu notável trabalho científico relativo ao desenvolvimento infantil, sustenta que a relação entre mãe e filho se inicia a partir da concepção e não do nascimento e, que é por meio desta relação que o recémnascido começa a compreender seu lugar no mundo.

Já Donald Woods Winnicott (1896-1971), pediatra e psicanalista, revolucionou a psicanálise ao analisar a relação de interpendência entre mãe e bebe, afirmando que "não há como descrever um bebê sem falar de sua mãe, pois, no início, o ambiente é a mãe e apenas gradualmente vai se transformando em algo externo e separado do bebê” (WINNICOTT, 1999).

O processo de amamentação, o espaço de tempo entre as mamadas, uma forma de segurar e outra, são todas experiências que fazem com que o bebê armazene em sua memória, adquirindo confiança ou falta de confiança no mundo (WINNICOTT, 1999).

Desde o século passado, após a realização de diversas pesquisas ${ }^{9}$, formou-se consenso científico a recomendação pela não institucionalização de crianças menores de 3 anos de idade,

\footnotetext{
${ }^{9}$ Durante os últimos 15 anos, foram publicados números estudos empíricos sobre crianças (por exemplo, Robertson e Robertson, 1967-72; Heinicke e Westhmeimer, 1966; Ainsworth, 1967; Ainsworth, Bell e Stayton, 1971, 1974; Blurton Jones, 1972), a teoria foi consideravelmente ampliada (por exemplo, Ainsworth, 1969; Bolwby, 1969, Bischof, 1975), e foi examidada a relação entre a teoria da ligação e a teoria da
} 
face aos nefastos efeitos produzidos pelo acolhimento, que comprovadamente se mostram mais prejudiciais à criança do que sua manutenção em sua família natural ou extensa, ainda que em condições de grave vulnerabilidade social:

\begin{abstract}
"com o passar dos anos, as sequelas marcadas na primeira infância com o abrigamento indevido, prolongado e agressivo, em muitos casos retornarão, uma vez que a moderna psicologia demonstra que os atendimentos mais efetivos, naturalmente devem considerar os rompimentos familiares precoces. Expressivos problemas comportamentais, distanciamento social, depressão stress angustia e outros problemas psicológicos podem ser consequências do precoce e inadequado rompimento familiar”. (BOWLBY, 2006, p. 23).
\end{abstract}

Assim, a abrupta e desnecessária ruptura dos laços materno-filiais, configuram forma de alienação parental estatal nos casos em que é promovida deliberadamente pelo Estado, em prejuízo da própria formação psicossocial da criança.

4.1.2 Da discriminação estrutural contida nos relatórios sociais que concluem pelo encaminhamento à família substituta

A hipótese que será aqui apresentada refere-se à alienação parental estatal praticada por meio de discriminação estrutural, em relação ao conteúdo de relatórios psicossociais e em relação ao próprio julgamento do caso, encaminhando o infante à família substituta, afastandoo definitivamente de sua família de origem.

A discriminação estrutural é revelada por padrões de comportamento, hábitos e regras no âmbito das instituições públicas que acabam atingindo alguns grupos de indivíduos relacionados por sua raça, cor, origem, gênero, ascendência ou situação social. O resultado desta espécie de discriminação é a marginalização desses indivíduos ou grupos impondo-lhes dificuldades maiores de acesso a direitos, garantias e oportunidades.

A aplicação das Medidas de Proteção, nos termos do artigo 100 do ECA/90, deve levar “em conta as necessidades pedagógicas, preferindo-se aquelas que visem ao fortalecimento dos vínculos familiares e comunitários”, com observância aos princípios da intervenção mínima e

dependência Maccoby e Masters, 1970; Gewirtz, 1972).(...) (John Bowlby, In “Formação e rompimento dos laços afetivos. Tradução de Alvaro Cabral, São Paulo: Martins Fontes, 2006, p. 170).

Revista Brasileira de Direito Civil em Perspectiva | e-ISSN: 2526-0243 | Salvador | v. 4 | n. 1 | p. 39 - 60 | Jan/Jun. 2018 
prevalência da família, como preveem o incisos VII e X, do parágrafo único do mencionado artigo 100 do ECA/90, e ainda o artigo 227 da CR/88.

Não encontra amparo constitucional, tampouco amparo legal, a determinação de acolhimento institucional cautelar ou preventivo baseados em valores apriorísticos, fundado em pré-conceito e que leva em consideração o que a pessoa da genitora é, e não o que ela efetivamente fez ou deixou de fazer nos cuidados com o filho.

A situação de vulnerabilidade social, por si só, não é capaz de autorizar o acolhimento institucional, uma vez que a marginalização da pobreza foi expressamente proibida pelo artigo 23 do ECA/90.

Preferir a segregação familiar, por meio do acolhimento institucional à proteção integral, por meio da aplicação de medidas de proteção (consubstanciada em políticas públicas efetivas para evitar que as situações de vulnerabilidade sofridas pela família acabem acarretando danos concretos ao infante), é inverter a lógica protecionista do ECA/90, com base em fundamento exclusivamente preconceituoso.

Família pobre também é família. Na miséria existe amor, existe união e existe direito a viver e conviver. Embora a CR/88 preceitue a existência digna, por meio do principio da dignidade da pessoa humana, não se pode impedir o direito de viver e conviver, ainda que sem a dignidade desejada pelo constituinte e raramente alcançada pelos constituídos. Compete ao Poder Público implementar políticas públicas capazes de proporcionar às famílias pobres condições para superar tais vulnerabilidades.

Após o acolhimento institucional, tem especial importância no trabalho de psicólogos e assistentes sociais dos abrigos na reintegração familiar das crianças colocadas sob sua guarda, com a obrigação de elaborar o Plano Individual de Atendimento (PIA) e os relatórios trimestrais acerca da situação do acolhimento institucional, os encaminhamentos feitos às famílias para a superação das vulnerabilidades e a conclusão pela possibilidade de reintegração familiar ou recomendação de encaminhamento para família substituta, na forma do parágrafo primeiro do artigo 19 do ECA/90.

Verifica-se, pois, que foi dado enorme poder para as entidades de acolhimento. Os relatórios sociais são importantes, mas não são a verdade e não são prova da ocorrência de um fato anterior ao acolhimento. Registram apenas um ponto de vista. Muitos relatórios que

Revista Brasileira de Direito Civil em Perspectiva | e-ISSN: 2526-0243 | Salvador | v. 4 | n. 1 | p. 39-60 | Jan/Jun. 2018 
concluem pelo encaminhamento à família substituta partem de premissas fundadas em boatos e ouvir dizer, sem identificação da fonte, e que passam a ser tratadas como verdade absoluta, independentemente de serem corroboradas por provas legais, sujeitas ao crivo do contraditório.

Da mesma forma, há certas presunções generalizadas que levam os técnicos das casas de acolhimento a concluírem pela impossibilidade de reintegração familiar sob o argumento de que as famílias que residem em ocupações precárias, ou pais que usam (ou usaram) drogas ou sejam portadores de alguma espécie de doença mental seriam incapazes de ser protetivos com seus próprios filhos.

Também no campo das presunções encontram-se aquelas ligadas à causa do acolhimento. Uma denúncia anônima, noticiando que a criança estaria sofrendo algum abuso físico, moral ou sexual, por exemplo, é capaz de importar o acolhimento e o encaminhamento à família substituta porque o genitor é abusador, é agressor ou é pedófilo, sem que tenha sido produzida uma única prova, ainda que indiciária.

Outras vezes, os relatórios que concluem pelo encaminhamento de infantes à família substituta revelam descrença preordenada e discursos pastorais, baseados num julgamento moral a partir do fato que gerou o acolhimento. São conceitos do senso comum e pouco técnicos, que acabam por fazer previsões futurológicas a partir de generalizações lançadas sobre os familiares, como “se a genitora agrediu o filho uma vez, certamente voltará a agredir” ou "se a progenitora materna não conseguiu proteger o neto da genitora drogada, se tiver a guarda, também não o fará” ou ainda, “se não conseguiu cuidar bem do primeiro filho, também não será capaz de cuidar deste bebe”.

Também é comum encontrar em relatórios sociais que recomendam o encaminhamento de determinada criança à família substituta por causas a que estão sujeitas centenas de outras crianças em sua condição social ou território, como "a criança ia pra escola descalça”; “a residência não tem banheiro”; “a menina não tem um quarto só pra ela” ou ainda, “as crianças dormem no mesmo cômodo dos pais”.

Percebe-se uma seletividade na escolha das premissas fáticas de onde as conclusões do relatório social são tiradas. O técnico omite informações que poderiam induzir a conclusão diversa. Em verdade, o técnico parte da conclusão prévia que já tem sobre o caso e só depois vai buscar os fatos que a corroboram.

Revista Brasileira de Direito Civil em Perspectiva | e-ISSN: 2526-0243 | Salvador | v. 4 | n. 1 | p. 39 - 60 | Jan/Jun. 2018 
Por fim, referidos relatórios revelam também que o trabalho de fortalecimento dos vínculos familiares, que é obrigatório, não é realizado ou é mal realizado. Há familiares extensos visitando a criança, mas não são avaliados, concentrando-se os técnicos exclusivamente na reintegração familiar aos genitores. Não esclarecem objetivamente o que cada familiar pretendente à guarda da criança institucionalizada deve fazer para que haja a reintegração familiar e ignoram a deficiência do serviço público existente na localidade de residência da família.

Todos os exemplos aqui citados foram extraídos de relatórios reais, que levaram ao encaminhamento de infantes a famílias substitutas na Vara da Infância e Juventude de Belo Horizonte, mas que em razão do sigilo imposto aos processos desta natureza, não podem ser aqui identificados.

Essas práticas revelam violência institucional e decorrem da adoção de modelos culturais elitistas que não refletem os costumes da maior parte da população.

O artigo 1513 do Código Civil ${ }^{10}$ estabeleceu o princípio da intervenção mínima do Estado no direito de família. Por este princípio, o Estado não deve cunhar standards aprioristicos de família ideal, não devendo interferir na estrutura familiar como interfere nas relações contratuais, por exemplo, sendo o dirigismo estatal contido pelo princípio da afetividade, limitador deste tipo de agressão estatal. (GAGLIANO, 2017, p. 1094). Por isso, revela-se ilegal a patologização de algumas formas de cuidado típicas de famílias pobres, como noções diferentes de higiene, alimentação e cuidados com a saúde e a liberdade das crianças para circular livremente pela comunidade.

Em todos estes casos verifica-se o indevido encaminhamento à família substituta de crianças que têm famílias que as amam e se interessam por elas, mas que foram dela afastadas por imposição do Estado, fundada em preconceitos, discriminação e violação de direitos, revelando a prática da alienação parental estatal e suas consequências irreversíveis para o indivíduo.

\subsubsection{O cerceamento de defesa das famílias nos procedimentos de Medida de Proteção de Acolhimento Institucional}

${ }^{10}$ CC 02, Art. 1.513. É defeso a qualquer pessoa, de direito público ou privado, interferir na comunhão de vida instituída pela família. 
A ausência de regulamentação especifica no ECA/90 acerca do procedimento para a apuração de situação de risco, aplicação de medida de acolhimento institucional e sua execução, é fator que provoca uma infinita diversidade de procedimentos criados aleatoriamente em cada Comarca ou cada Tribunal.

Há Varas da Infância que ainda utilizam-se dos Pedidos de Providências, procedimento instituído pelo antigo Código de Menores, revogado pelo ECA/90. Outras utilizam um procedimento de jurisdição voluntária, como é o caso da Comarca Rio de Janeiro. Outras, optaram por aplicar o procedimento ordinário ou o cautelar, com fundamento na subsidiariedade do Código de Processo Civil, prevista no artigo 152 do ECA/90.

Outras Comarcas optaram pela utilização de procedimentos verificatórios e de investigação judicial preliminar ${ }^{11}$ para verificação da ocorrência (ou não) de ameaça ou violação de direitos, e a necessidade de aplicação de Medida de Acolhimento Institucional, como é o caso de Belo Horizonte.

Neste último caso é que se revela, com mais frequência, a prática reiterada de alienação parental estatal por meio de violência institucional. Tratando-se de mero procedimento de investigação, não é assegurado o direito à ampla defesa e ao contraditório aos genitores e familiares, como determina o artigo 153 do ECA/90. Neste sentido, vale conferir decisões proferidas pela Vara da Infância Cível de Belo Horizonte ${ }^{12}$

“(...) 3. O genitor alega jamais ter sido chamado para participar do presente processo, apesar de ter apresentado defesa. Destaca-se que o procedimento de Medidas de Proteção destina-se apenas à aplicação das medidas protetivas, não imponto o afastamento definitivo da família natural. Trata-se de um procedimento destinado à efetivação de direitos das crianças e adolescentes, nos moldes de um inquérito policial, não podendo ser confundido com um procedimento administrativo. $\mathrm{O}$ afastamento definitivo da família é consequência da Ação de Destituição do Poder Familiar, ação autônoma, sujeita ao contraditório e à ampla defesa.”

\footnotetext{
11 “Por outro lado, a despeito da ausência de previsão legal, sustentamos ser possível, viável e até mesmo recomendável a instauração, até mesmo de ofício, de procedimentos verificatórios ou de investigação judicial preliminar para apuração de ocorrência (ou não) de ameaça ou violação dos direitos da criança e do adolescente (art. 70 do Estatuto da Criança e do Adolescente)”. Guaraci De Campos Vianna, Poder Normativo Da Justiça Da Infância E Juventude. Disponível em: < http://www.tjrj.jus.br/c/document_library/get_file?uuid=0a810a94-f9494190-acdf-360867bc7063\&groupId=10136> Acesso em 29 de março de 2018

12 Os processos e partes de onde foram extraídos estes trechos de decisões judiciais não serão identificados em razão do sigilo imposto aos procedimentos da infância e juventude.
} 
“(...) Além disso, como o procedimento de providencia se destina apenas a aplicar as medidas protetivas necessárias as crianças e adolescentes, não impondo o afastamento definitivo da família natural, não há um rito adequado estipulado para essas ações na lei.

O "processo de providencia" foi criado pelo Estatuto da Criança e do Adolescente nos moldes de um inquérito policial, e se destina a efetivação de uma investigação de cunho social e familiar, que não traz consequências praticas punitivas para os pais ou responsáveis.

$(\ldots)$ "

Outra situação problemática que envolve estes casos é que as famílias submetidas a este procedimento, por serem extremamente carentes, quase já não têm garantido acesso à qualquer forma de defesa formal durante o processo de acolhimento institucional. E a Defensoria Pública também não é notificada dos acolhimentos institucionais para a defesa imediata das famílias e das crianças, como o é para o réu preso, na forma do art. 306 do Código de Processo Penal.

É certo que boa parte das crianças que lotam as casas de acolhimento não foram abandonadas por suas famílias. O que se nota é que são crianças oriundas de famílias pobres e têm sido tratadas pelo Estado como objeto e não como sujeitos de direito, num retrocesso à doutrina menorista de outrora.

O artigo 87 do revogado Código de Menores é que regulava este procedimento e previa: “se a medida judicial a ser adotada não corresponder a procedimento previsto nesta ou em outra lei, a autoridade judiciária poderá investigar livremente os fatos e ordenar, de ofício, as providências".

Tal poder inquisitivo foi propositadamente rechaçado pelo ECA/90, deixando claro que visava acabar com os procedimentos meramente verificatórios, que eram praxe instituída pelo revogado Código de Menores. Contudo, boa parte da justiça da infância e juventude resistiu à evolução legislativa, sendo necessário que a lei $\mathrm{n}^{\circ}$ 12.010/2009 abolisse expressamente essa prática, incluindo o parágrafo único ao artigo 153, que passou deixar claro que a possibilidade do juiz investigar fatos ou ordenar de ofício providências não se aplica "para o fim de afastamento da criança ou do adolescente de sua família de origem e em outros procedimentos necessariamente contenciosos”. 
O procedimento de providência, previsto no caput do artigo 153 do ECA/90, refere-se tão somente a medidas inominadas, não previstas expressamente pelo Estatuto, mas que embora não tenham procedimento de tramitação especificado, têm como pressuposto elementar a ausência de lide.

Por óbvio, nos procedimentos que possam resultar no afastamento de crianças e adolescentes do convívio familiar, ainda que temporariamente, exige-se respeito ao contraditório e ao devido processo legal constitucional, direito humano fundamental, previsto no artigo $5^{\circ}$, LX da CR/88.

Outrossim, com a instituição do Estado Democrático de Direito pela CR/88, tornou-se paradoxal a existência de procedimentos investigatórios conduzidos pelo próprio juiz que julgará o caso. O exercício regular do contraditório e o respeito ao devido processo legal são os únicos instrumentos capazes de evitar a configuração da alienação parental praticada pelo Estado.

\section{CONCLUSÃO}

O direito à igualdade, a não discriminação, ao devido processo legal e ao contraditório são conquistas fruto da evolução histórica da humanidade. Da mesma forma, o direito de agrupar-se em família e dela não ser retirado compulsoriamente pelo Estado.

É certo que há casos em que o afastamento da criança de sua família de origem é necessário para preservar-lhe direitos, mas a interferência estatal deve ser limitada aos casos estritamente legais, desde que verificada a concreta necessidade e, jamais, alcançar situações fundadas em pré-conceitos em razão de condições financeiras, sociais, origem, crença, gênero, cor ou qualquer outra forma de discriminação.

A atuação estatal no âmbito desta interferência deve ser primorosa. A aplicação e a execução de medidas de proteção de acolhimento institucional de crianças e adolescentes e, principalmente, a conclusão pelo encaminhamento à família substituta, devem ser cuidadosamente verificadas, com a observância do devido processo legal, com zelo para não incorrer em julgamentos morais, subjetivos e discriminatórios. 
As consequências pela pratica da alienação parental estatal são danosas e, por vezes, irreversíveis, aos indivíduos a elas submetidos e, por esta razão, ensejam a responsabilização civil, penal e criminal dos responsáveis.

Para tanto, necessário que os profissionais envolvidos no processo, inclusive juízes, promotores, defensores, advogados, psicólogos, assistentes sociais e demais servidores, sejam altamente qualificados e especializados no tema.

A natural tendência humana de julgar, pré-julgar e discriminar só pode ser controlada com o diálogo franco, direto, aberto e constante entre todos os agentes envolvidos no processo de acolhimento institucional, sem prejuízo da necessária capacitação continuada.

As arbitrariedades que vêm sendo praticadas nos procedimentos de acolhimento institucional e denunciadas neste estudo merecem especial atenção do Estado, sob pena de serem reveladas ainda inúmeras outras formas de alienação parental estatal, além das praticadas por discriminação estrutural ou violência institucional. Nesta seara, o Estado Democrático Brasileiro transforma-se num verdadeiro Estado de Coisas Inconstitucional, violando frontalmente os valores supremos da sociedade fraterna, pluralista e sem preconceitos almejados pela Carta Magna.

\section{REFERÊNCIAS}

BELO HORIZONTE. Prefeitura Municipal. Secretaria Adjunta de Assistência Social. 2017 CARVALHO FILHO, José dos Santos. Manual de Direito Administrativo. $17^{\mathrm{a}}$ Ed. Rio de Janeiro: Lúmen Juris, 2007.

DIAS, Maria Berenice. Manual de Direito das Famílias. 8a ed. São Paulo: Editora Revista dos Tribunais, 2011 DINIZ, Maria Helena. Curso de Direito Civil brasileiro: Direito de Família. 23. ed. São Paulo: Saraiva, 2008 GAGLIANO, Pablo Stolze. Manual de direito civil; volume único. São Paulo, Saraiva, 2017. LÔBO, Paulo. Direito Civil: família. 2. ed. São Paulo: Saraiva, 2009.

MELLO, Luiz Gonzaga. Antropologia Cultural: Iniciação, teoria e temas. - 7 ed. Petrópolis: Vozes, 2009.

MINAS GERAIS. Tribunal de Justiça do Estado de Minas Gerais. SOFES - Serviço de Orientação e Fiscalização de Entidades. 2017

MULTEDO, Renata Vilela. Liberdade e Familia. Limites para a intervenção do estado nas relações conjugais e parentais. Ed. Processo. Rio de Janeiro. 2017

Revista Brasileira de Direito Civil em Perspectiva | e-ISSN: 2526-0243 | Salvador | v. 4 | n. 1 | p. 39 -60 | Jan/Jun. 2018 
PEREIRA, Caio Mário da Silva. Instituições de direito civil. Vol V. 25. Ed. Rio de Janeiro. Forense, 2017

PEREIRA, Rodrigo da Cunha. Princípios Fundamentais norteadores do Direito de Família. Belo Horizonte. Saraiva. 2012.

TARTUCE, Flávio. Direito Civil, v. 5: Direito de Família. 12 ed. Rio de Janeiro. Forense, 2017

TRINDADE, Jorge. Incesto e alienação parental: realidades que a justiça insiste em não ver. / Maria Berenice Dias, coordenação. São Paulo. Editora Revista dos Tribunais. 2007.

WINNICOTT, Donald W. Privação e delinqüência. $3^{\text {a }}$ Ed. São Paulo. Martins Fontes. 1999 ZANARDO, G. L. P., Calderón, M., Nadal, A. H. R., \& Habigzang, L. F. (2017). Violência obstétrica no Brasil: uma revisão narrativa. Disponível em: < http://www.scielo.br/pdf/psoc/v29/1807-0310-psoc-29-e155043.pdf> Acesso em 25 de novembro de 2017 